\title{
elyra
}

\section{A escrita da vida como risco no espaço - a leitura como performance dos diários de Carolina Maria de Jesus e Maura Lopes Cançado}

\section{Mariana Patrício Fernandes}

Ufrj

Resumo: O presente artigo pretende pensar modos performáticos de leitura dos diários Quarto de Despejo: Diário de uma Favelada de Carolina Maria de Jesus e Hospício é Deus: Diário I de Maura Lopes Cançado. Escritos no início dos anos 1960, esses diários entretém uma relação heterotópica com a literatura, suspendendo distinções previamente estabelecidas entre escrita e vida. É nesse sentido que se torna possível entrever sua dimensão performática, exigindo uma leitura que também se coloque em risco diante dessa suspensão, em seu caráter permeado de incertezas e vulnerabilidades.

Palavras-chave: diário, testemunho, Carolina Maria de Jesus, Maura Lopes Cançado

Abstract: The present article intends to approach performatic modes of reading Quarto de despejo: Diário de Uma Favelada by Carolina Maria de Jesus and Hospício é Deus: Diário / by Maura Lopes Cançado. Written in the early 1960s, these journals entertain a heterotopic relationship with Literature, suspending previously established distinctions between writing and life. In that way it becomes possible to glimpse its performative dimension, requiring a reading mode that also puts itself at risk by facing uncertainty and vulnerability.

Keywords: diary, testimony, Carolina Maria de Jesus, Maura Lopes Cançado 
A comida no estômago é como combustível nas máquinas. Passei a trabalhar mais depressa. O meu corpo deixou de pesar. Comecei a andar mais depressa. Eu tinha a impressão que eu deslizava no espaço. Comecei sorrir como se tivesse presenciado um lindo espetáculo.

Carolina Maria de Jesus

ĺamos ensaiar o Hamlet. Sai com o livro (bem aparelhada) (...) sabia o perigo que representava a cachoeira. Um doente atirara-se quebrando a perna. (...)

Resolvi despir-me. Antes imaginei a cena: caras retorcidas. Atirei as calças compridas, perdi a blusa na correnteza. Não me senti envergonhada. Vi-me bonita. Branca, respingada de lama. Desafiava-os em minha nudez. Selvagem! Insolente! Inocentemente nua.

Um passo a mais e poderia morrer. Escureceu aumentando o frio. Pensei: andar nas sombras é descansar o dia de presenças. E saí mitologicamente das águas. Plena. Brincava antes do ataque. Enfermeiros viriam. Certo. A correnteza dava leveza"

Maura Lopes Cançado

\section{A leitura impossível, o leitor que dança}

No início da década de 1960, as escritoras Carolina Maria de Jesus e Maura Lopes Cançado escrevem seus diários sobre dois espaços heterotópicos ${ }^{1}$ : a favela e o hospício. Seus escritos se convertem nas publicações, Quarto de despejo: diário de uma favelada (1960) e Hospício é deus: diário I (1965).

Mineiras do interior, oriundas de classes sociais distintas, caminham em direção ao sul, marcadas pela paradoxal solidão e vulnerabilidade que se entrelaça ao desejo de inserção na cena literária. Escrever sobre os espaços que as recebem, a favela do Canindé, em São Paulo, no caso de Carolina Maria de Jesus, e o Hospital psiquiátrico do Engenho de 
Dentro no Rio de Janeiro, no caso de Maura Lopes Cançado, é paradoxalmente e simultaneamente um modo de se equilibrar sobre eles, sem desmoronar, e um gesto de isolamento, criando fissuras no solo comum em relação a seus contemporâneos, fossem eles os moradores do Canindé, os internos do hospital psiquiátrico ou os escritores em atividade no Brasil.

Esse artigo se propõe a entrever como essas fissuras possibilitam aberturas nos modos de experimentar a relação entre escrita e vida, em sua dimensão estética e política, a partir do gesto dessas duas mulheres escritoras. Em um país em ebulição, entre utopias de modernização democrática que se enfrentam com forças conservadoras que poucos anos mais tarde apoiariam o golpe militar, os diários ocupam a cena literária produzindo pequenas fendas, que são, contudo, irreparáveis, permanecendo abertas até hoje. $\mathrm{Na}$ relação tortuosa que essas escrituras autobiográficas mantêm com as grandes utopias modernistas, é possível entrever um desejo de transformação de dicotomias e sistemas excludentes e totalizantes definidores da relação entre arte e vida, política e subjetividade. Torção do estabelecido que se mantém pulsante na atualidade, como modo de escapar à asfixia e ao engessamento material e subjetivo, criando novas possibilidades de vida.

Para tal se faz crucial pensar a sua leitura também como gesto que se arrisca no espaço literário, escapando às definições que reforçariam o isolamento a que foram submetidas suas autoras e seus escritos.

Recebidos com interesse pela mídia e pelo público, mas ignorados pela crítica, esses textos permanecem como heterotopias literárias, caminhando pelas bordas do reconhecimento. Caráter limítrofe que oscila entre fulguração e apagamento, e diante do qual nos indagamos, o que há nessas escritas que tensionam as margens do que entendemos por literatura e como nos posicionamos diante desse tensionamento. ${ }^{2}$

Posicionamento aqui entendido por sua dimensão ética, mas também e sobretudo, como posição do corpo. "É com o corpo certamente que se lê", escreve Roland Barthes sobre a leitura. A leitura como movimento erótico que transtorna o corpo, sem o despedaçar. O que a leitura faz desmoronar, segundo Barthes, é a estrutura (2004:38).

O desmoronar da estrutura que impede o fechamento de categorias lógicas transcendentais parece ser o motor mesmo desses diários que convocam a presença do 
leitor, diante dessa "hemorragia permanente" (Barthes), na qual se misturam história, poesia, autobiografia e ficção. Como uma força que aproxima aquilo que as estruturas sociais deveriam manter a distância, os diários de Jesus e Cançado convocam a presença do leitor que adentra, transtornado, um espaço simultaneamente literário e real, forçando-o assim a traçar sozinho seu modo de colocá-los em relação.

Pensar esse transtorno do corpo-leitor em desequilíbrio, sem uma cadeira para sentar, é em certa medida atravessar a advertência lançada por Reynaldo Jardim no belo prefácio de Hospício é Deus, quando escreve:

Eis o grito de socorro sem o objeto gritante (...) e se a mão amiga estende o abrigo, eis o abrigo devorado, e a mão. Ei-la colocando na mão que a saúda o punhal e o pedido de eutanásia (...) No fundo, em verdade, vos digo, o que se houve é um pungente pedido de socorro de quem não estando em perigo não pode ser atendido. O melhor para continuar dormindo tranquilamente é não virar a página. Mais que um prefácio, isto é uma advertência: este é um livro perigoso, feito para comprometer irremediavelmente a sua consciência (apudCançado 2015: 35 )

O perigo do livro, que compromete a consciência, é o reconhecimento da impotência diante de um texto dentro do qual a voz que fala já não está aí, desapareceu no tecido literário, tornou-se impessoal. No entanto, tem nome, corpo, singularidade irredutível que resiste à despersonalização das instituições que insistem em transformá-las em estatística.

É sobre uma dupla impossibilidade que nós, os leitores desses diários, vacilamos: já não podemos lê-los como denúncia nem tampouco como literatura pura. Não somos salvadores, tampouco somos especialistas. É sobre ela, contudo, que reside a possibilidade de fazer dançar em desequilíbrio um corpo que já tão pouco encontra um chão seguro no plano concreto de uma atualidade que não cessa de desmoronar. Quem sabe se é possível encontrar novas veredas que indicam modos de viver junto, nos quais é possível estar só sem estar só, desfazendo ilusões de auto suficiência, ou de comunidade totalitária que amalgamam subjetividades e exterminam diferenças.

Seria possível entrever aí uma imbricação entre a escrita e a leitura dos diários e a arte da performance? Para seguir esse fio condutor no labirinto da proposta será preciso antes de tudo, repensar, a partir de Jesus e Cançado, o que é que estamos chamando de diário e a que nomeamos de arte da performance. 


\title{
Diário como performance
}

\begin{abstract}
Levanto-me da cama para escrever a qualquer hora, escrevo páginas e páginas - depois rasgo mais da metade, respeitando apenas, quase sempre, aquelas em que registro fatos ou minhas relações com as pessoas. Justamente nestas relações está contida toda a minha superficialidade (...) Será deveras lastimoso se este diário for publicado. Não é, absolutamente um diário íntimo, mas tão apenas o diário de uma hospiciada(...) Seria verdadeiramente escandaloso meu diário íntimo - até para mim mesma, porquanto sou multivalente, não me reconheço de uma página para outra. Prefiro guardar minhas verdades, não pô-las no papel"
\end{abstract}

(Cançado1992:.121)

Seria possível dizer que essa dupla impossibilidade de leitura pode ser lida como marca de escritos que entrelaçam de modo heterodoxo autobiografia e ficção? Diana Klinger em Escrita de si como performance (2008) analisa o modo como a prosa latinomericana do início dos anos 2000 responde paradoxalmente tanto ao narcisismo midiático que marca o século XXI, quanto à crítica estruturalista do sujeito, expressa nas teses de Foucault e Barthes sobre o desaparecimento do autor. Na prosa autoficcional dos anos 2000, em autores como Cesar Aira e Silviano Santiago, o sujeito reapareceria, segundo Klinger, sem, no entanto, se reconfigurar como referência anterior ao texto. Nesse paradoxo, essas escritas tangenciariam a performance tanto no modo como pensada pela teoria queer (a identidade como performatividade que subverte o modelo normativo), quanto pelas artes cênicas, no seu esforço de reconectar arte e vida.

No texto de autoficção, entendido nesse sentido, quebra-se o caráter naturalizado da autobiografia numa forma discursiva que ao mesmo tempo exibe o sujeito e o questiona, ou seja, que expõe a subjetividade e a escritura como processos em construção. Assim, a obra de autoficção também é comparável à arte da performance na medida em que ambos se apresentam como textos inacabados, improvisados, work in progress, como se o leitor assistisse "ao vivo" ao processo da escrita (...) Isso é característico, também, de certa literatura que Josefina Ludmer (2007) chama de "pósautônoma". Estas obras performáticas podem ser lidas junto com aquelas narrativas que, segundo 
Ludmer (2007), “aparecem como literatura mas não podem ser lidas com os critérios ou com as categorias literárias (específicas da literatura) como autor, obra, estilo, escrita, texto e sentido. E, portanto, é impossível Ihes atribuir um 'valor literário': já não tem, para essas escritas, literatura boa ou ruim". Sendo assim, a autoficção mostraria algo a mais do que uma tendência da narrativa contemporânea. Talvez ela seja um dos signos de um esgotamento da cultura moderna das letras. (Klinger 2008: 27)

A performance é pensada aqui como uma escrita que se apresenta em processo, inacabada, exigindo a presença do outro para existir. Como um gesto de abertura no texto, que estabelece relação transgressora em relação às referencialidades que evoca. Ausência de original que suspende ordenações e hierarquias e impede, como escreve Josefina Ludmer, a circunscrição em categorias literárias bem delimitadas (Ibidem).

O jogo com a intimidade autobiográfica como suspensão de certezas em relação à experiência literária também é marca da poesia de Ana Cristina Cesar. Em Singular $e$ Anônimo (2006), Silviano Santiago parte da leitura do poema Correspondência completa para pensar no caráter transitivo da linguagem, em perpétua travessia em direção ao leitor. Travessia que não estabelece, contudo, ancoragem no real - ponto de partida ou ponto de chegada. A travessia de que fala Santiago a partir do poema de Cesar é da ordem da aventura, que exige que o leitor se desloque tanto de uma leitura autoritária que exige respostas do poema, quanto de uma mistisficadora, mantendo intacta a linguagem, isolando o texto do mundo. Em Correspondência completa essas posturas são encenadas por Gil e Mary, de quem a remetente se queixa ao seu destinatário:

Fica difícil fazer literatura tendo Gil como Leitor. Ele lê para desvendar mistérios e faz perguntas capciosas, pensando que cada verso oculta sintomas, segredos biográficos. Não perdoa o hermetismo. Não se confessa os próprios sentimentos. Já Mary me lê toda como literatura pura. Não entende as referências mais diretas (Cesar 2002: 90)

Sem poder lançar mão das duas estratégias de leitura caberia ao leitor se lançar no risco de abrir o caixão e deixar circular novamente o ar, sem aniquilar o poema. Experiência, que é da ordem do gesto, como escreve Giorgio Agamben, em Profanações: "O lugar do poema (...) não está nem no texto, nem no autor, e nem no leitor, mas no gesto no qual autor e leitor se põem em jogo no texto e infinitamente se retraem" (Agamben 2000: 93). 
Esse colocar-se em jogo, deslocando-se do seu lugar identitário, transporta a leitura para um exercício performático, em que se suspendem as fronteiras do possível. Seria preciso pensar ainda no modo como essa suspensão põe em risco também as próprias fronteiras do que se entende por vida, adquirindo um caráter fortemente político. É nesse sentido que se abre a sua dimensão performática, entendendo aqui a performance como marca de experimentos que questionam os suportes tradicionais que autonomizam o fazer artístico e a própria noção de obra de arte $^{3}$. Questionamento que ecoa um desejo de intervenção no tempo e no espaço simultâneos à obra, e de transformação, ainda que efêmera, das formas de relação entre as esferas da vida. ${ }^{4}$

Eleonora Fabião em Performance e teatro: Poéticas e políticas da cena contemporânea pensa a performance como um gesto que busca

\footnotetext{
maneiras alternativas de lidar com o estabelecido, de experimentar estados psicofísicos alterados, de criar situações que disseminam dissonâncias diversas: dissonâncias de ordem econômica, emocional, biológica, ideológica, psicológica, espiritual, identitária, sexual, política, estética, social, racial... (...) expandem a idéia do que seja ação artística e "artisticidade" da ação, bem como a idéia de corpo e "politicidade" do corpo. (Fabião 2008:237).
}

Esse embaralhar de fronteiras permite, como escreve Ana Bernstein, que, enquanto gênero, a performance abrigue uma multiplicidade de formas, carregando, entretanto, como marca constitutiva uma linguagem que se converte em ato (a partir dos estudos de Austin) e que "quase sempre exibe uma forte atualidade e é bastante responsiva às questões políticas e sociais do momento" (Bernstein 2001:92).

Trata-se aqui de um duplo gesto, portanto. Pensar na dimensão performática das escritas de Maura Lopes Cançado e Carolina Maria de Jesus é também reconhecer a necessidade de atualizar performativamente o gesto de leitura.

Nas duas direções faz-se necessário questionar os limites e possibilidades que o gênero diário coloca a essa aventura. A própria noção de intimidade é posta em questão. Os cadernos em que escrevem agenciam o desejo de estar só com o desejo de intervir no espaço público, e nesse agenciamento colocam em questão os lugares que lhes são destinados pela sociedade brasileira como mulher negra, pobre e favelada em Carolina Maria de Jesus e como interna de um hospital psiquiátrico em Maura Lopes Cançado. Os 
diários aqui são escritas híbridas entre ficção, testemunho, ensaio, poesia e denúncia, que rompem com a lógica do possível na literatura e na vida. Não sem ameaçar a ordem das coisas, despertando assim sua desconfiança: eu desêjei vários empregos. Não aceitaram-me por causa da minha linguagem poética escreve Jesus. Ou ainda:

Um homem não há de gostar de uma mulher que não pode passar sem ler. E que levanta pra escrever. E que deita com lápis e papel debaixo do travesseiro. Por isso eu prefiro viver só para meu ideal. (Jesus 1993: 44)

Aqui estou de novo nesta 'cidade triste'. É daqui que escrevo. Não sei se rasgarei estas páginas, se as darei ao médico, se as guardarei para serem lidas mais tarde. Ignoro se tenho algum valor, ainda no sofrimento (...) Com o que escrevo poderia mandar aos 'que não sabem' uma mensagem de nosso mundo sombrio. Dizem que escrevo bem. Não sei. Muitas internadas escrevem. O que escrevem não chega a ninguém. (Cançado 1992: 32)

É a partir desse hibridismo heterodoxo que entrevejo sua dimensão performática, tomando aqui a ideia de performance em sua dimensão estético-política como escreve Bernstein ao analisar os trabalhos das artistas norte-americanas Karen Finley, Peggy Shaw e Penny Arcade:

(...) Contrariamente à ideia de uma armadilha em auto-absorção que Richard Sennett define como "narcisismo" e que leva à inação do corpo social, uma parte significativa da arte da performance nos Estados Unidos nas últimas duas décadas vem intervindo politicamente de maneira significativa e constante na esfera pública. (...) A performance solo autobiográfica tem, de fato, desempenhado uma função crítica na criação de um espaço discursivo para minorias que não se enquadram na normatividade do discurso ideológico dominante. (Bernstein, 2001:92)

A escrita se apresenta aqui como modo de (re)existência em territórios marcados pela despersonalização e pelo silenciamento. Escrever é, para além da inscrição de sentidos em um espaço outro hermeticamente fechado, um ato de pausa e ressignificação desses espaços, a céu aberto, não mais em território protegido do escritório, do quarto, ou da sala de estudos.

Talvez o diário, com suas entradas, cuja marca dos dias permite uma justaposição heterogênea entre temas e formas, possibilite essa intervenção tanto no espaço literário, 
como no espaço público. Entretanto, o faz, colocando-se em risco, expondo-se em sua vulnerabilidade literária e subjetiva, facilmente silenciada por leituras fetichizantes que fecham novamente as janelas do texto, encerrando as suas autoras nas gavetas do exotismo. Gesto esse que pode ser visto como leitura totalizante e silenciadoradessas escritas que procuram a todo momento abrir meios de passagem, traçar rotas de fuga do cárcere, não se deixar capturar. Como escrevia Maura Lopes Cançado no conto Espelho Morto do livro Sofredor do ver:

Fugir é encontrar pessoas com as quais possa falar, sem que minhas palavras se percam no vácuo, inúteis. Porque vivo sozinha em um mundo cada vez mais estranho, fantástico, monstruoso. Não que as coisas tenham se modificado tanto. Desde menina este encarceramento me sufoca, minha coragem foi sempre formada do desejo de evasão, o desespero de fuga deu-me forças até hoje" (Cançado 1968: 37).

\section{De onde se lê}

Pensar a performance em sua conexão com a atualidade pela qual é atravessada e a qual responde e resiste é também pôr em jogo o modo pelo que entendemos a relação espaço-tempo que configura o que estamos nomeando de atual. Segundo Michel Foucault, o desejo de pensar a atualidade realizando uma "ontologia do presente" foi via aberta por Kant, invadido pelas noticias da revolução francesa (Foucault 1983: 2). Segundo o filósofo, é então que

(...) parece surgir pela primeira vez a questão do presente, a questão da atualidade: que é que se passa hoje? Que é que se passa agora? E o que é este 'agora', no interior do qual estamos uns e outros; e que define o momento em que escrevo" (Foucault 1984: 103)

A revolução francesa como acontecimento, segundo Foucault, embaralha definitivamente a noção de historicidade, da relação entre passado e futuro

e separará da contingência que nos fez ser como somos, [ levando-nos] à possibilidade de não sê-lo mais, de pensar e atuar diferente. Não é buscar tornar possível uma metafísica que finalmente se converte numa ciência, mas sim buscar dar novos ímpetos, tanto quanto seja possível, ao indefinido trabalho da liberdade. (apud Cardoso 1995:54) 
Este indefinido trabalho da liberdade que mobilizou movimentos artísticos e políticos ao longo do século $\mathrm{XX}$, inspirando outros modos de pensar a relação entre arte e vida, suspende ou embaralha fronteiras bem definidas entre viver, pensar, criar, trabalhar. Suspensão que muitas vezes põe a nu os modos de ser a partir dos quais se organizam as relações entre essas esferas da vida.

Há aqui um questionamento da representação em sua dimensão estética, política e filosófica. Seja almejando a autonomia da forma, ou ao fim da hierarquia dos temas a serem representados. Descentramento da experiência que se desdobra em uma infinidade de possibilidades de relação entre vida e arte, no qual a única constante é a suspensão de certezas.

Fora do centro da representação política, Maura Lopes Cançado e Carolina Maria de Jesus escrevem. Suas escritas têm consciência de que suas vozes não possuem a legitimidade das vozes masculinas que emanam do centro. Ausência de legitimidade que fere e despersonaliza, silenciando.

- Quando eu era menina o meu sonho era ser homem para defender o Brasil porque eu lia a história do Brasil e ficava sabendo que existia a Guerra. Só lia nomes masculinos como defensor da pátria. Então eu dizia para a minha mãe.

- Por que a senhora não faz eu virar homem.

Ela dizia:

- Se você passar por debaixo do arco-íris você vira homem.

Quando o arco-íris surgia eu ia correndo na sua direção. Mas o arco-íris estava sempre distanciando. Igual os políticos diante do povo. Eu cansava e sentava. Depois começava a chorar. Mas o povo não deve cansar. Não deve chorar. Deve lutar para melhorar o Brasil para os nossos filhos não sofrer o que estamos sofrendo. Eu voltava e dizia para a mamãe

- O arco-íris foge de mim. (Jesus 1993: 48)

O "povo não deve cansar" de Carolina Maria de Jesus se encontra com "O ainda assim falo" de Maura Lopes Cançado. Como falar sem ser ouvida?É a partir dessa pergunta que podemos, quem sabe, entrever novos destinos para a noção de intimidade. Não mais pensada em sua dimensão privada, em oposição à esfera pública, como se fosse possível isolar o individuo e o coletivo, mas como uma experiência de si. Nessa experiência torna-se possível insistir em modos de resistência de uma vida que não mais se inscreve no curso da 
história pelos grandes feitos dos homens importantes, mas por sua singularidade irredutível aos modelos pré-existentes.

Nesse sentido, o recurso ao diário permite entrever essa vida não exemplar, mas que se apresenta em processo de transformação. Alberto Giordano, ao analisar o diário do escritor argentino Rodolfo Walsh, encontra aí a possibilidade de conjurar o demônio sempre presente da impossibilidade de escrita. Conjuração que se dá também pela possibilidade de escapar dos estereótipos do escritor engajado, necessária para recuperar a alegria e o desejo de escrita que impulsionarão a escrita do romance:

Walsh estava muito atento às ameaças de despersonalização que sofrem os que, por falarem sempre em nome dos demais, deixam de falar de si mesmos, por si mesmos. Justamente por isso escrevia um diário ao qual confiava a "renovada crônica de como as coisas passaram pela gente". A escrita dos diários como resistência ao poder, sedutor e imperceptível dos estereótipos que desenham, com traços grossos a figura do revolucionário exemplar. (Giordano 2016: 23)

O resgatar a alegria da escrita,evitando os estereótipos em Cançado e Jesus, parte do sentido oposto da escrita de Walsh, o escritor exemplar, mas se encontra no mesmo ponto em que o diário permite, nas palavras de Giordano: "a experimentação performativa na qual o escritor de diários coloca à prova a consistência ética do que lhe acontece enquanto ensaia transformações" (idem: 22).

Essa experimentação performativa suspende definições precisas entre escrita e vida e encontra um espaço-outro, quem sabe, uma heterotopia, para seguir com Foucault, a partir do qual é possível contestar separações fixas.

Nesse sentido, pensando em como a leitura pode também se converter em gesto que se arrisca nessa suspensão, torna-se urgente que o leitor se desloque das posturas autoritárias ou mistificadoras, encerrando essas escritas nas gavetas onde dormem as autobiografias das mulheres excêntricas. É nesse momento que a autonomia da experiência literária pode ser pensada como chave de abertura, lembrando também que essas autoras escreveram outros textos ficcionais com os quais os diários se relacionam. ${ }^{5}$

Nem só vida, nem só ficção, trata-se de reconhecer a existência desses outros espaços geralmente sufocados por uma ordem patriarcal e racista. Ordem que por sua vez é ameaçada por esses escritos que transgridem seu funcionamento hierárquico, justapondo 
considerações sobre o preço do feijão, tratamentos psiquiátricos, memória política e divagações poéticas.

Lançados nos anos 1960, esses escritos ecoam na atualidade em que esta ordem se encontra, paradoxalmente, mais feroz e vulnerável do que nunca. Nos últimos anos, as ruas do país foram palco de manifestações políticas heterogêneas, dando a sensação de que o solo comum da sociedade brasileira começava a craquelar, despertando forças políticas, afetivas e estéticas de intensidades e tonalidades bastante distintas entre si. Forças estas que se manifestam em ondas que compõem o mar revolto da atualidade, cujos desdobramentos ainda não conhecemos. Entre elas uma toma forma no final de 2015 conferindo novo ímpeto ao movimento feminista sendo cunhada pela imprensa como $a$ primavera das mulheres. Em novembro desse ano as ruas foram ocupadas por corpos e vozes que não se faziam representar nas esferas macropolíticas. A primeira presidenta eleita na história do país enfrentava dificuldades de governabilidade que levariam à sua deposição, menos de um ano depois. A contraposição entre as instâncias de poder majoritariamente masculina e a força insurgente de mulheres de diversas gerações e classes sociais que ocupavam as ruas ganhava, contudo, uma dimensão incontornável e plural.

Pensar, a partir de Carolina Maria de Jesus e Maura Lopes Cançado, a escrita da vida como performance que intervém e é atravessada pelo espaço público no Brasil se faz urgente uma vez que as próprias noções de coisa pública, comunidade e política se encontram sob profunda ameaça de aniquilamento. É preciso repensar a dimensão afetiva, ética e estética da política e isso tem sido feito, há muito tempo, por mulheres que excluídas das instâncias de poder não se deixaram esmagar em sua potência criativa e contestadora. Pensar a escrita como performance é também pensar o leitor como participante da ação, ressignificando o exercício da crítica diante desse espectro.

O espaço público como terreno aberto à entradas e saídas que permite a coexistência intensiva de subjetividades em pleno exercício da diferença precisa ser repensado, revivido, uma vez que está ameaçado de extinção. Contra as forças políticas que insistem em privatizar o comum, seria preciso apostar na comunalidade de uma experiência que reinventa a relação entre intimidade e exterioridade, pessoal e político, público e privado. 
A escrita da vida como risco no espaço - a leitura como performance dos diários de Carolina Maria de Jesus e Maura Lopes Cançado

Fiz a comida. Achei bonito a gordurafringindo na panela. Que espetáculo deslumbrante! As crianças sorrindo vendo a comida ferver nas panelas. Ainda mais quando é arroz e feijão. É um dia de festa para eles. (Jesus 1993: 38)

\section{Notas}

${ }^{1}$ Parte-se aqui da noção de heterotopia desenvolvida por Michel Foucault em As palavras e as coisas e O Corpo Utópico, as heterotopias. As heterotopias teriam como regra geral justapor em um lugar real vários espaços que, normalmente, seriam ou deveriam ser incompatíveis. São contestações míticas e reais do espaço em que vivemos.(Foucault 2013: 24). Lançamos mão aqui do conceito Foucaultiano para pensar na estreita relação que os diários de Cançado e Jesus entretém com os espaços onde são escritos. Espaços de exclusão da pobreza (a favela) e da loucura (o hospício) que ao mesmo tempo desnudam ordenações aparentemente naturais que estruturam as relações no sistema capitalista. É através da escrita que esses espaços podem ser abertos e as fronteiras tornadas vibráteis nos dois diários.

2 No ensaio Anos dourados: mulheres malditas, diários esquecidos. Carolina Maria de Jesus e Maura Lopes Cançado. O historiador José Carlos Sebe Bon Meihy reflete sobre as condições de possibilidade de publicação desses escritos, bem como o porquê de permanecerem marginais "abandonados até mesmo pelas mais atentas feministas":

\footnotetext{
Sem alternativas de competição no círculo dos autores consagrados, ou das emergentes mulheres que assumiam com valentia a competitividade do mercado, seria pela raia da exceção que se dariam os caminhos para escritoras "desviadas" aparecerem no concorrido clã dos personagens de relevo (...)

o mesmo ambiente que via nascer a bossa nova e a jovem guarda; que assistia o Brasil ser, pela primeira vez campeão mundial de futebol, de boxe e de tênis: que constituía as primeiras grandes indústrias automobilísticas instaladas, exatamente no momento que despontava a arquitetura de Brasília com "a capital da esperança", deixava espaço para expressões de duas desajustadas mulheres. (Meihy, s.d.:1)
}

${ }^{3}$ Para Jacques Rancière esse questionamento é próprio da concepção mesma de arte moderna. Embaralhar e desorganizar a partilha do sensível seria próprio à experiência estética como proposto por Schiller, a partir de Kant, nas Cartas sobre a Educação Estética do Homem. A noção de liberdade levantada por Rancière,inspira-se na formulação de Schiller a respeito da relação entre arte e vida, a partir da ideia de jogo. É o aspecto livre da 
estética que permite criar novas tramas que trançam a relação entre arte, vida e política. Esse aspecto livre se relaciona com a noção de autonomia da arte, mas a partir de uma noção singular de autonomia. Não se trata da autonomia da obra, nem da razão livre subjugando a anarquia da sensação. A autonomia é da experiência estética estritamente relacionada a uma revogação do poder:

O "aspecto livre" se coloca à nossa frente, intocável, inacessível ao nosso conhecimento, nossas intenções e desejos. O sujeito recebe a promessa da posse de um novo mundo por essa figura que ele não pode possuir de maneira alguma. A deusa e o espectador, o jogo livre e o aspecto livre, são pegos juntos em um sensorium específico, anulando as oposições entre atividade e passividade, vontade e resistência. A "autonomia da arte" e a "promessa da política" não são contrapostas. A autonomia é a autonomia da experiência, não a da obra de arte. (Rancière 2011:6)

${ }^{4}$ Impossível não evocar aqui as Correspondências entre o poeta e dramaturgo AntoninArtaud e o editor da Nouvelle RevueFrançaise (NRF), Jacques Rivière. Conhecido por revolucionar o teatro no século XX, com a critica feroz ao drama burguês e à representação, a primeira publicação de Artaud é justamente suas correspondências onde convoca o editor a deslocar-se da sua autoridade tradicional de leitor para entrever outros modos de escuta do poema. Seria então preciso pensar o literário em relação com o "grito da vida mesmo", infectada por uma doença que "remove as palavras" e "desenraiza o pensamento" (Artaud 2017: 39). Segundo Ana Kiffer,esse processo de erosão do pensamento que configura-se como perda de si é paradoxalmente, em Artaud, o único caminho para "se reconfigurar subjetivamente".

${ }^{5}$ Maura Lopes Cançado publica em 1968 o livro de contos O sofredor do ver e Carolina Maria de Jesus publica em 1963 o romance Pedaços da fome, em ambos as narrativas em terceira pessoa ressignificam as experiências da loucura e da fome presentes nos diários. 


\section{Bibliografia}

Artaud, Antonin (2017), A perda de si: cartas de AntoninArtaud, seleção, organização e prefácio de Ana Kiffer, Rio de Janeiro, Rocco.

Agamben, Giorgio (2000), Profanações, São Paulo, Boitempo Editorial.

Barthes, Roland (2004), O rumor da língua, São Paulo, Martins Fontes.

Bernstein, Ana (2001), "A Performance Solo e o Sujeito Autobiográfico", Sala Preta (USP), v. 1, 91-103.

Cançado, Maura Lopes (2015), Hospício é Deus: Diário I, Rio de Janeiro, Editora Autêntica, [1992].

-- O Sofredor do Ver (1968), Rio de Janeiro, José Álvaro.

Cardoso, Irene de Arruda Ribeiro (1995), "Foucault e a noção de acontecimento", Tempo Social Rev. Sociol. USP, S. Paulo, 7(1-2), 53-66, outubro.

César, Ana Cristina (2002), A teus pés, São Paulo, Editora Ática.

Fabião, Eleonora (2009), "Performance e teatro: Poéticas e políticas da cena contemporânea", Sala Preta (USP), v. 8, 235-246.

Foucault, Michel (2013), O corpo utópico, as heterotopias, São Paulo, Martins Fontes.

-- As palavras e as coisas (2000), São Paulo, Martins Fontes.

-- "O que é o lluminismo" (1984), "Qu'est-ce que les Lumières?», in : Magazine Littéraire, n. 207, mai 1984, 35-39. (Retirado do curso de 5 de Janeiro de 1983, no Collège de France). Traduzido a partir de FOUCAULT, Michel, Dits et Écrits, Paris: Gallimard, 1994, Vol. IV, 679688, por Wanderson Flor do nascimento. <http://michelfoucault.weebly.com/ uploads/1/3/2/1/13213792/iluminismo.pdf>

Giordano, Alberto (2016), A senha dos solitários, Rio de Janeiro, Papéis Selvagens.

Jesus, Carolina Maria de (1993), Quarto de despejo: diário de uma favelada. Diário de uma favelada, São Paulo, Editora Ática.

-- Pedaços da fome (1963), São Paulo, Editora Áquila Ltda. 
Klinger, Diana (2008), "Escrita de si como performance", Revista Brasileira de Literatura Comparada, n.12.

Meihy, José Carlos, “Anos dourados, mulheres malditas, diários esquecidos, Carolina Maria de Jesus e Maura Lopes Cançado", in: <http://www.albertolinscaldas.unir.br/ zonadeimpacto/anosdourados.htm>

Rancière, Jacques (2009), A partilha do sensível: estética e política, São Paulo, Editora 34.

-- "A revolução estética e seus resultados" (2011), tradução de Flávia Ragazzo, $<$ revolucoes.org.br>.

Mariana Patrício Fernandes é doutora em Letras pela Pontifícia Universidade Católica do Rio de Janeiro (2012).Professora Substituta do departamento de Ciência da Literatura na Universidade Federal do Rio de Janeiro e Professora da disciplina literatura e outras artes na Pós-Graduação Lato Senso, Literatura Arte e Pensamento Contemporâneo no CCE/PUCRio. Atualmente vem pesquisando a relação entre escrita e corpo nas imbricações entre literatura, dança e performance na contemporaneidade, a partir das autoras Maura Lopes Cançado, Carolina Maria de Jesus e da coreógrafa, cineasta e performer Yvonne Rainer. 